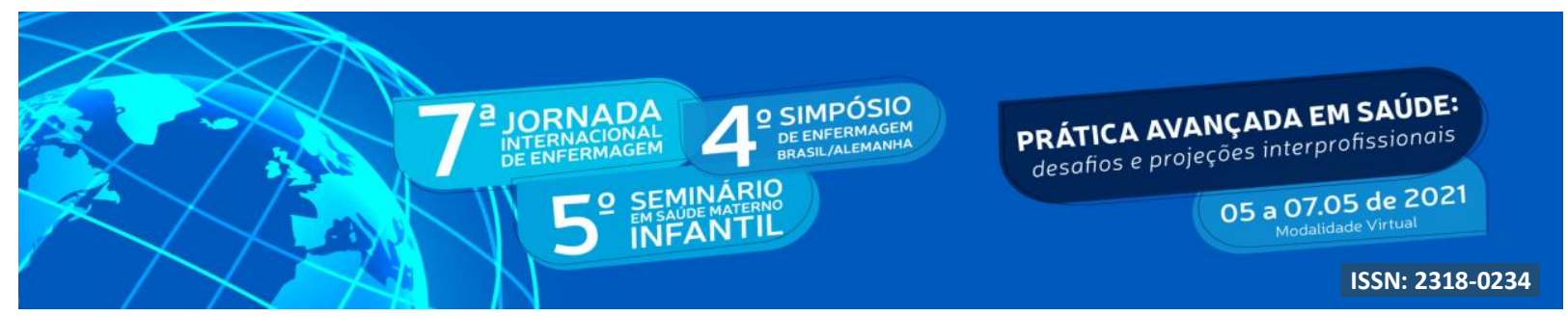

DOI: http://doi.org/10.48195/jie2021-112

\title{
A SAÚDE MENTAL DOS PROFESSORES E ESTUDANTES EM TEMPOS DE PANDEMIA $^{1}$
}

\section{Carolina Montedo²; Karinne Duarte da Rocha ${ }^{3}$; Luíse Pivetta Gastaldo ${ }^{4}$; Marcele Pereira da Rosa Zucolotto ${ }^{5}$, Josiane Lieberknecht Wathier Abaid ${ }^{6}$.}

\begin{abstract}
RESUMO
A pandemia do Covid-19 causou um grande impacto nas instituições educacionais, as quais tiveram que se adaptar de forma ágil e inesperada. Devido a esse acontecimento foi preciso pensar em atividades pedagógicas mediadas pelo uso da internet, aplicadas em função das restrições impostas pelo distanciamento social. Além dos métodos de ensino, o planejamento pedagógico dos docentes precisou ser readaptado de forma acelerada, gerando insegurança tanto para os professores como para os alunos. Os professores precisaram migrar da escola para trabalhar dentro de suas casas, assim, a delimitação de tempo e espaço em relação ao trabalho também foi alterada, gerando um aumento do volume de trabalho significativo. Os alunos tiveram o contato com os colegas restrito, alterando assim as formas tradicionais de aprender e originando grande ansiedade. Todos esses aspectos impactam a saúde mental do docente e do discente, dessa forma, esse trabalho tem o intuito de relatar a experiência na produção de cards que alertem sobre a temática da saúde mental dos docentes e discentes durante a pandemia do Covid-19.
\end{abstract}

Palavras-chave: Saúde Mental; Docente; Discente; Covid-19; Extensão.

\begin{abstract}
The Covid-19 pandemic had a major impact on educational institutions, which had to adapt in an agile and unexpected way. Due to this event, it was necessary to think about pedagogical activities mediated by the use of the internet, applied due to the restrictions imposed by social distance. In addition to teaching methods, the pedagogical planning of teachers needed to be readapted in an accelerated manner, generating insecurity for both teachers and students. Teachers had to migrate from school to work inside their homes, thus, the delimitation of time and space in relation to work was also changed, generating a significant increase in the volume of work. The students had restricted contact with their colleagues, thus changing the traditional ways of learning and causing great anxiety. All of these aspects impact the mental health of the teacher and the student, thus, this work aims to report the experience in the production of cards that warn about the theme of mental health of teachers and students during the Covid-19 pandemic.
\end{abstract}

\footnotetext{
${ }^{1}$ Educação e promoção da saúde

${ }^{2}$ Acadêmica do Curso de Psicologia - Universidade Franciscana. Email: carolinamontedo@ gmail.com

${ }^{3}$ Acadêmica do Curso de Psicologia - Universidade Franciscana. Email: karinneduartedarocha@ hotmail.com

${ }^{4}$ Acadêmica do Curso de Psicologia - Universidade Franciscana. E-mail: luise.gastaldo2304@gmail.com

${ }^{5}$ Docente do curso de Psicologia. - Universidade Franciscana. E-mail: marcele.rosa@ufn.edu.br

${ }^{6}$ Orientadora. Doutora em Psicologia e docente do curso de Psicologia. - Universidade Franciscana. E-mail: josianelieb@ufn.edu.br 


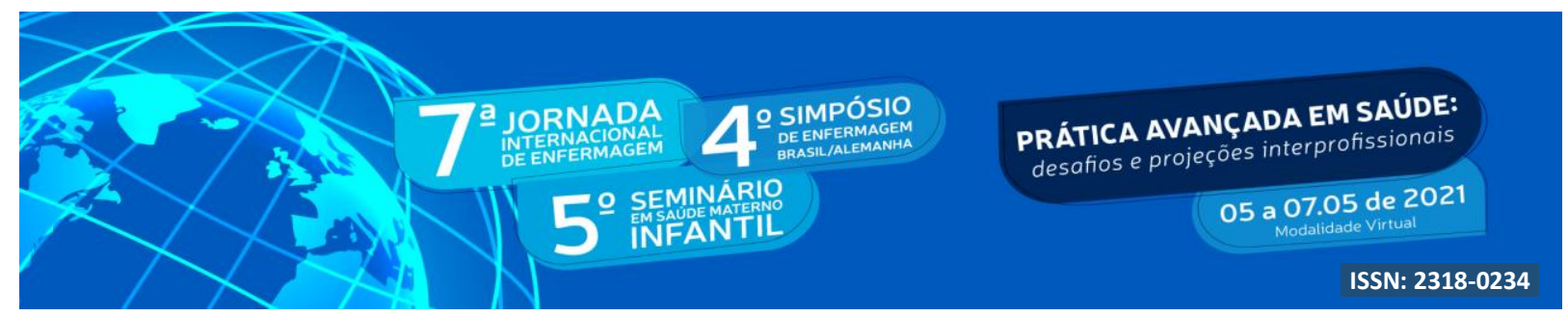

Key Words: Mental health; Teacher; Student; Covid-19; Extension.

\section{INTRODUÇÃO}

Este texto pretende relatar a atuação na disciplina extensionista de Psicologia nos Processos Educacionais do curso de Psicologia da Universidade Franciscana. As atividades foram desenvolvidas na cidade de Santa Maria, RS de forma remota devido ao contexto da pandemia da Covid-19. Objetiva-se por meio dessas ações extensionistas incentivar a interação entre instituições, nesse caso a escola de Educação Básica e a Universidade Franciscana, possibilitando a interação entre os sujeitos do contexto escolar e os acadêmicos do Curso de Psicologia, além da promoção de intervenções e o intercâmbio de experiências e a construção de conhecimentos e ideias. Tais ações potencialmente promovem uma análise reflexiva acadêmica, enquanto futuros psicólogos, diante do contexto do trabalho e de suas implicações sobre os processos educacionais e a saúde mental dos alunos e professores durante a pandemia do Covid-19.

A profissão docente é considerada pela Organização Internacional do Trabalho (OIT), como uma das mais estressantes (Gil-Monte, 2008). Segundo Dworak e Camargo (2017), esse fato muitas vezes acaba interferindo na prática laboral do docente, estabelecendo o desconforto no ambiente de trabalho. Caldeira (2013) ainda enfatiza que o dia a dia em sala de aula está repleto de acontecimentos significativos, não só na vida do professor, mas também na do estudante. As manifestações de afeto, que muitas vezes estão presentes na relação professor-estudante, podem contribuir tanto para o aprendizado do estudante quanto para a evolução do professor como educador.

Porém, como esse momento de pandemia exige que haja uma reinvenção por parte dos profissionais da área escolar, o Boletim de Conjuntura ressalta que todos os envolvidos no processo educacional devem unir forças no sentido de pensar e de refletir sobre as estratégias, adaptáveis a cada realidade, para que os impactos dessa crise ocasionada pelo novo coronavírus sejam, pelo menos, atenuados (BOCA, 2020). Durante a pandemia do novo Coronavírus, esses aspectos se tornaram ainda mais desafiadores aos discentes, e principalmente, aos docentes. Considerando estes pressupostos, foi estabelecido o objetivo 


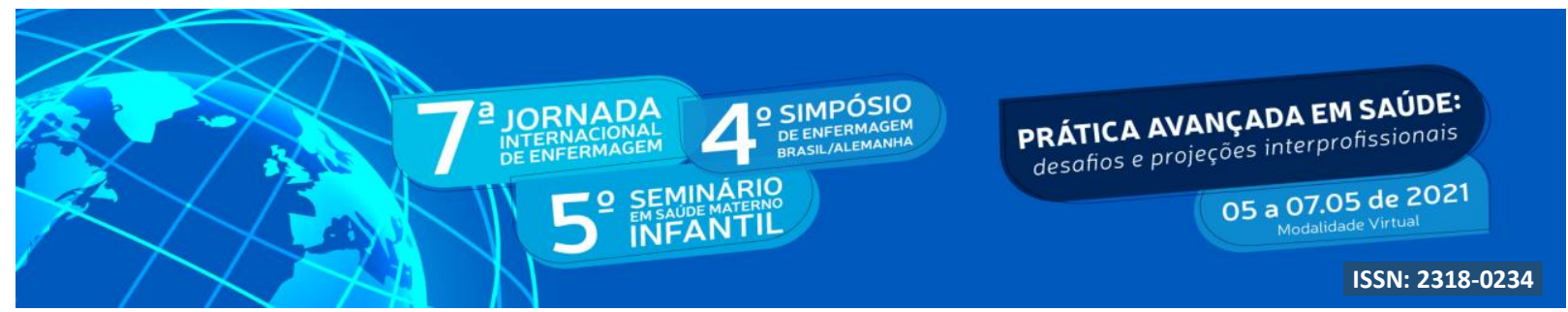

deste trabalho para correlacionar elementos encontrados nos estudos científicos e acadêmicos com a prática da extensão no que se refere aos impactos da pandemia na saúde mental do professor e do estudante.

Com o objetivo de viabilizar uma maior atenção à saúde mental dos docentes e discentes durante a pandemia e o isolamento social, foram construídos cards sobre a temática. Sendo assim, o presente estudo tem como objetivo descrever a experiência de produção de cards para a escola sobre a temática citada.

\section{OBJETIVO}

\section{Objetivo Geral}

Relatar a experiência na disciplina extensionista de Psicologia nos Processos Educacionais do curso de Psicologia da Universidade Franciscana.

\section{Objetivos Específicos} pandemia;

Identificar os principais fatores de sofrimento psíquico professores e alunos durante a

Refletir sobre a saúde mental de professores e alunos durante a pandemia do covid-19;

Destacar as possibilidades de intervenções do psicólogo com docentes e discentes na educação básica durante a pandemia da covid-19.

\section{METODOLOGIA}

O presente artigo foi produzido a partir do desenvolvimento de uma prática extensionista da disciplina de Psicologia nos Processos Educacionais. Foram realizados estudos e leituras referentes a essa temática, além de um acompanhamento e auxílio fornecidos pela professora da disciplina em questão. As práticas ocorreram junto a uma escola municipal de uma cidade do interior do Rio Grande do Sul, de forma remota.

As práticas realizadas também foram desenvolvidas a partir do Estágio Específico I e II, prescrito como requisito parcial para a conclusão do curso de Psicologia da Universidade Franciscana., com ênfase nos processos educacionais, o qual "prevê que os discentes tenham um maior contato com o exercício da prática acadêmica para o desenvolvimento de avaliações e intervenções em psicologia escolar e educacional a fim de contribuir com os diferentes aspectos que permeiam o processo de ensino e aprendizagem, prevenção ao sofrimento psíquico e qualidade de vida dos 


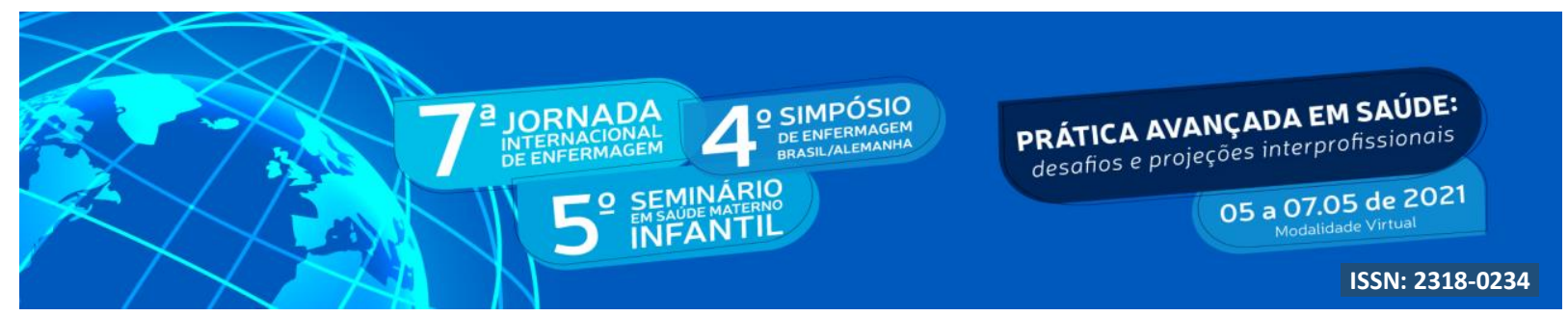

atores envolvidos." (UNIVERSIDADE FRANCISCANA, 2016, p.30)

O referido trabalho possui natureza descritiva e qualitativa como estudo das referências utilizadas por alguns autores da psicologia, vinculados à área da saúde mental e educacional, se deu por considerar que a pesquisa bibliográfica possibilita um maior alcance das informações, e a utilização de dados dispersos em diversas publicações (GIL, 2002).

\section{RESULTADOS E DISCUSSÃO}

A partir do contato com a equipe diretiva, com alguns professores da escola e alguns alunos, foram pensadas estratégias a fim de promover uma reflexão sobre a saúde mental dos professores e dos alunos em tempos de pandemia do Covid-19. Ao final, foram produzidos cards a fim de alertar os professores, os estudantes e a comunidade escolar sobre o impacto da pandemia na área educacional e também propor sugestões de ações que auxiliem tanto professores quanto estudantes a melhor lidar com o enfrentamento desse momento atípico e as consequentes mudanças que ele traz.

Por meio do contato com a equipe diretiva da escola, e principalmente, dos acolhimentos de estágio realizados com uma professora, foi possível perceber que a necessidade do corpo docente em buscar auxílio psicológico aumentou devido ao momento atípico de pandemia que estamos vivenciando no Brasil e no mundo. Isso desacomodou os professores, que tiveram de se reinventar e se adaptar à nova realidade, fazendo uso da tecnologia para ensinar de forma remota, à distância. Como houve certa dificuldade em lidar com as novas formas de ensinar, o papel da psicologia em oferecer apoio emocional e compreensão empática aos educadores tornou-se ainda mais essencial.

De modo geral, o que mais ficou evidente nos acolhimentos, tanto com os alunos quanto com a professora foi o medo. O medo que eles relatavam sentir frente ao desconhecido, diante da súbita e jamais vista pandemia do Coronavírus e das bruscas mudanças que ela veio produzindo no estilo de vida de todos. Maldini (2020) afirma que a iminência de contágio por uma doença desconhecida fez com que os indivíduos se sentissem receosos com o incerto e as consequências futuras que trará para suas vidas. Esse medo, provocado pela situação estressante, é normal e saudável, segundo os especialistas, desde que não seja excessivo. 


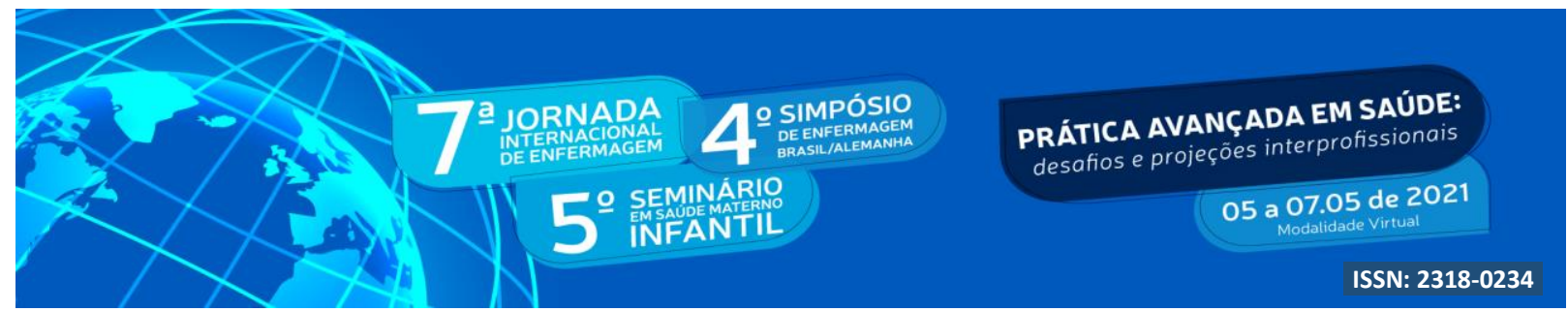

Iannini (2020) acrescenta "No contexto atual, o perigo é invisível e, por também ser desconhecido, os indivíduos não estão preparados para lidar com ele, já que, na nossa cultura, não há disponível um repertório transmitido simbolicamente para enfrentá-lo".

De um lado, a educadora em questão trazia em seu discurso a principal queixa da maior parte dos professores: a sobrecarga de atividades advinda do contexto pandêmico, já que agora, devido às medidas preventivas de distanciamento e isolamento social, a escola passou a adentrar a casa dos professores em forma de videoconferências e aulas remotas. De outro, os alunos acolhidos relatavam em uma só voz o quanto o contato físico e a presença de seus colegas e amigos, que antes era frequente, lhes fazia falta. Em ambos os casos, todos se questionavam quando tudo isso se findaria para que finalmente pudessem retornar à sua rotina habitual anterior.

Apesar das incertezas e inseguranças que esse momento provocou não somente nos indivíduos acolhidos, mas também em nós, enquanto futuras psicólogas, alguns aspectos observados que colaboraram com o exercício do nosso trabalho merecem destaque. Um deles diz respeito à aceitação da nossa proposta diferenciada de acolhimento remoto. Pode-se dizer que os alunos e, especialmente, a professora acolhida receberam de forma positiva a ideia dos acolhimentos online, mostrando-se bem abertos às reflexões que fazíamos acerca do novo cenário que vivenciamos e também às sugestões que dávamos a eles para adaptar-se da melhor maneira possível ao atual contexto. Buscamos pensar, juntamente com eles, quais eram seus principais hobbies, a exemplo de praticar atividades físicas e desenhar e, a partir disso, propor a eles que os fizessem algumas vezes na semana como forma de aliviar a angústia e a ansiedade decorrentes da nova rotina que adotaram.

Outro ponto de suma relevância que foi percebido foi a grande capacidade simbólica que os alunos acolhidos possuíam. Isso se mostrou ainda mais evidente em um dos alunos que possuía apenas 8 anos de idade, e já era capaz de identificar e refletir acerca de seus próprios sentimentos. Piaget (1975) define a função simbólica como a capacidade que a criança adquire de diferenciar significantes e significados. Por meio de suas manifestações, a criança torna-se capaz de representar um significado (objeto, acontecimento) através de um significante diferenciado e apropriado para essa representação. Dessa forma, Freitas (2010) complementa que a criança de dois a sete anos, aproximadamente, passa a contar com a 


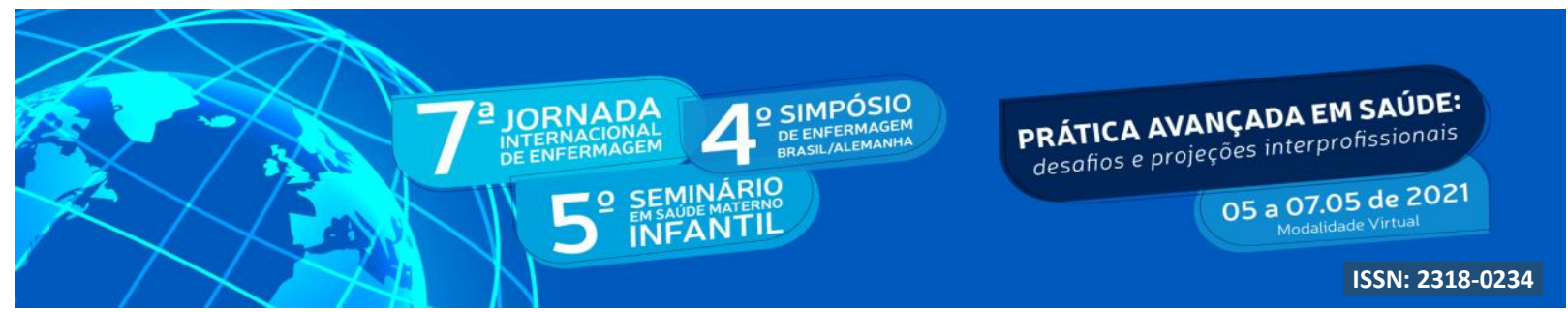

possibilidade de representar as ações, as situações e os fatos da vida dela, ao manifestá-las por meio da construção da imagem mental, imitação diferida, jogo simbólico, linguagem e desenho (condutas de representação). É possível dizer, assim, que os alunos em questão foram capazes de representar o significado dos acontecimentos de sua nova rotina por meio do significante da linguagem, tanto oral (nas videoconferências realizadas) quanto escrita (por meio de chats e redes sociais, configurados como o principal meio de comunicação).

Por conseguinte, fica claro que o papel da psicologia em acolher, escutar e auxiliar os indivíduos acolhidos a lidar com esse momento atípico mostrou-se extremamente relevante. Vale frisar também que a realização do nosso trabalho enquanto futuras psicólogas só foi possível graças à disposição, ao empenho e à boa capacidade de reflexão que os envolvidos no processo de acolhimento demonstraram. Esses fatores, sem dúvida, colaboraram em muito para que o trabalho da psicologia no contexto escolar se desse de forma eficaz, dentro do possível, considerando a limitação de recursos que a atual circunstância nos proporcionou, e também contribuíram no sentido de enriquecer o nosso conhecimento e a nossa experiência como futuras profissionais da área da Psicologia.

Nesse sentido, foram elaborados dois cards informativos que estão ilustrados abaixo como produto do trabalho realizado, sendo um direcionado aos professores (Figura 1) e outro aos alunos (Figura 2), com o intuito de alertar à escola em questão e à comunidade em geral os impactos negativos que a pandemia causou nos educadores e também nos estudantes em geral. 


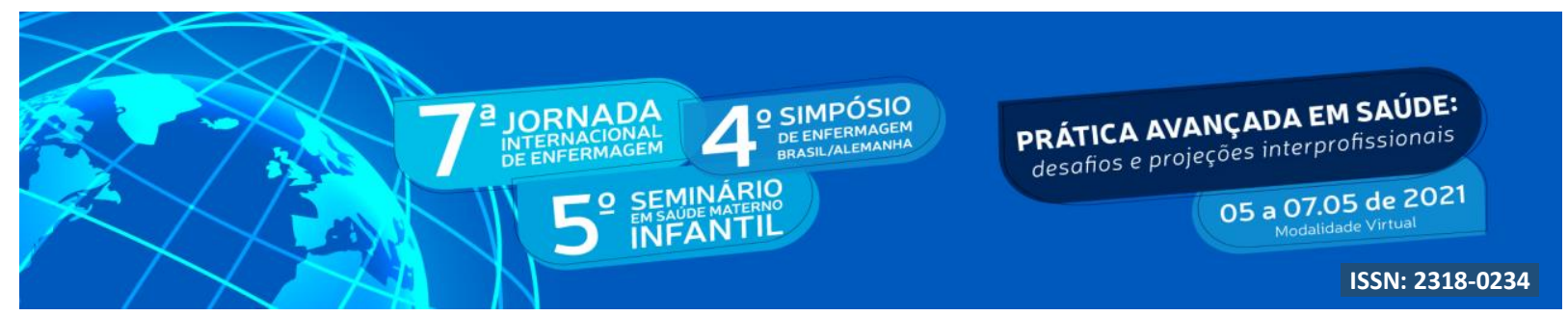

Figura1- Card Reflexivo sobre a saúde mental dos docentes na Pandemia do Covid-19

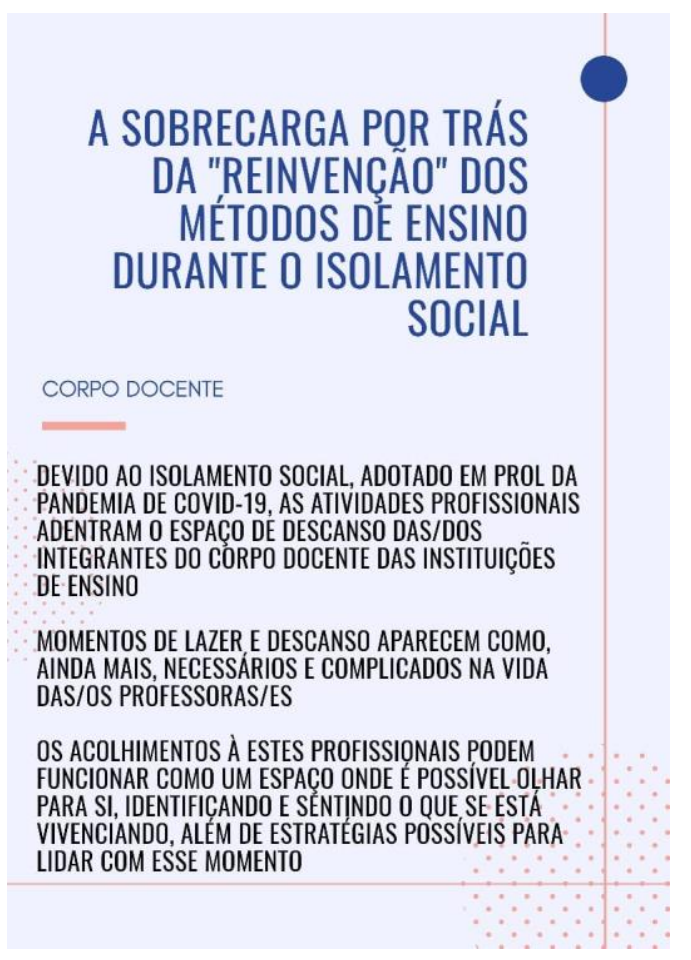

Figura 2- Card Reflexivo sobre a saúde mental dos discentes na Pandemia do Covid-19

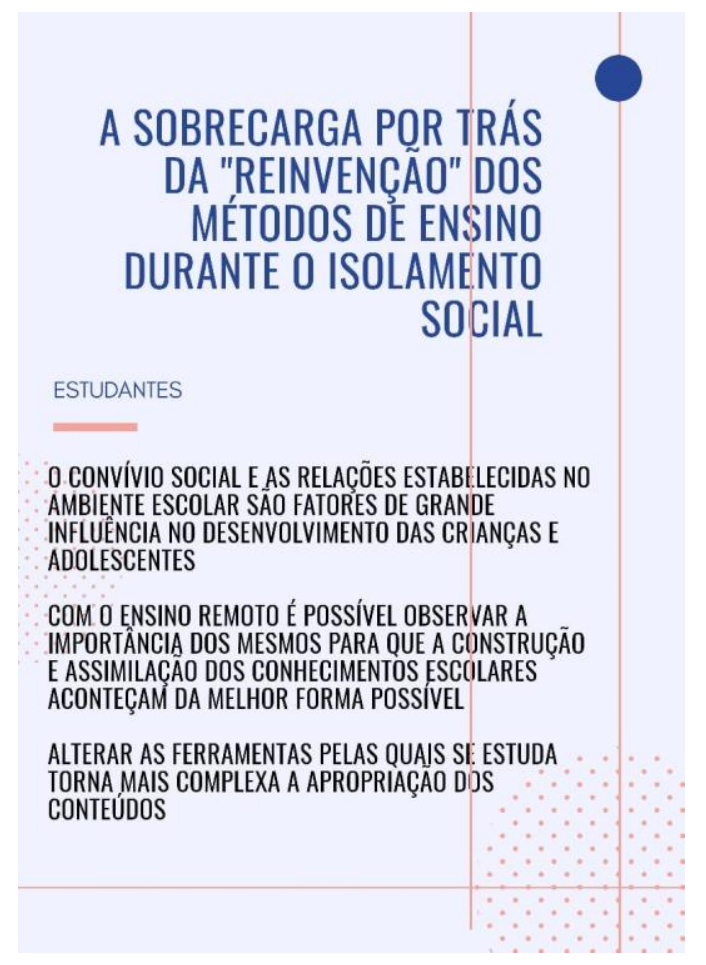




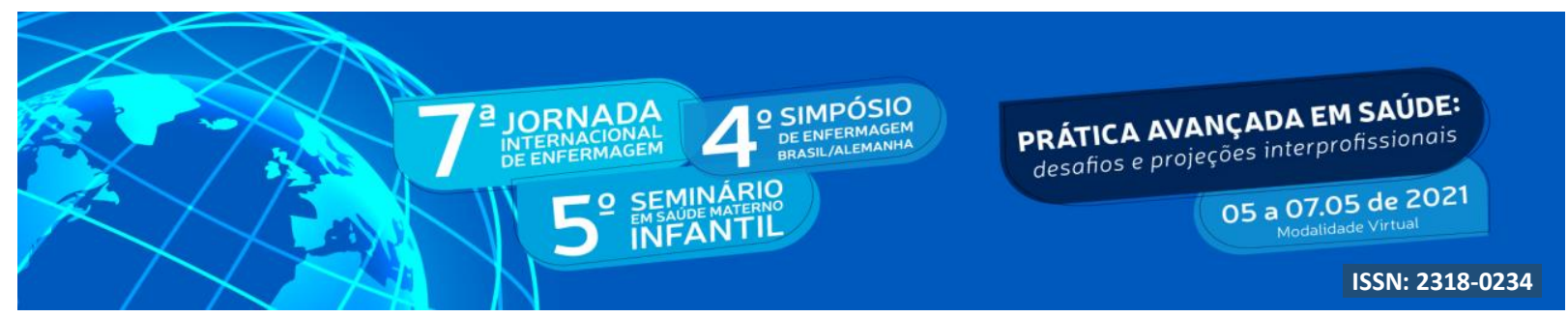

\section{CONCLUSÃO}

A necessidade de atitudes preventivas diárias para manutenção da saúde física, mental e social no ambiente laboral é essencial em todas as profissões, no entanto as consequências desta sobrecarga para os professores já instaurada antes mesmo da pandemia somadas as todas as mudanças atuais por vezes vem incidindo a um sofrimento psíquico e a transtornos e doenças psicossomáticas decorrentes do trabalho que consequentemente leva o profissional prejuízo tanto para a saúde dos docentes como para os alunos e a escola como um todo.

Destaca-se assim a necessidade da atuação e do acompanhamento do psicólogo escolar com os professores e alunos a fim de promover estratégias que possam contribuir com a saúde mental dos mesmos e no restabelecimento do bem-estar emocional.

\section{REFERÊNCIAS}

CALDEIRA, J. S. Relação Professor-Aluno: uma reflexão sobre a importância da afetividade no processo de ensino aprendizagem. Anais do XI Congresso Nacional de Educação (XI EDUCERE) / II Seminário Internacional de Representações Sociais, Subjetividade e Educação (II SIRSSE) / do IV Seminário Internacional sobre Profissionalização Docente (IV SIPD). Curitiba: PUC-PR, 2013.

DWORAK, A.P; CAMARGO, B. C. Mal-Estar docente: Um olhar dos professores. Anais do Congresso Nacional de Educação p.6912-24, 2007.

FREITAS, M. L. L. U. A evolução do jogo simbólico na criança. Revista Ciências e Cognição, Rio de Janeiro, v. 15, n. 3, p. 145-163, 2010.

GIL, A. C. Como elaborar projetos de pesquisa. 4. ed. São Paulo: Atlas, 2002.

GIL-MONTE, P. R. El síndrome de quemarse por el trabajo (burnout) como fenómeno transcultural. Información Psicológica, 91-92, 4-11, 2008.

MALDINI, Giovana. Efeito pandemia: medo aparece com mais intensidade na população. 2020. Faculdade de Medicina, Universidade Federal de Minas Gerais, Minas Gerais, 2020. Disponível em: https://www.medicina.ufmg.br/efeito-pandemia-medo-aparece-com-maisintensidade-na-populacao. 


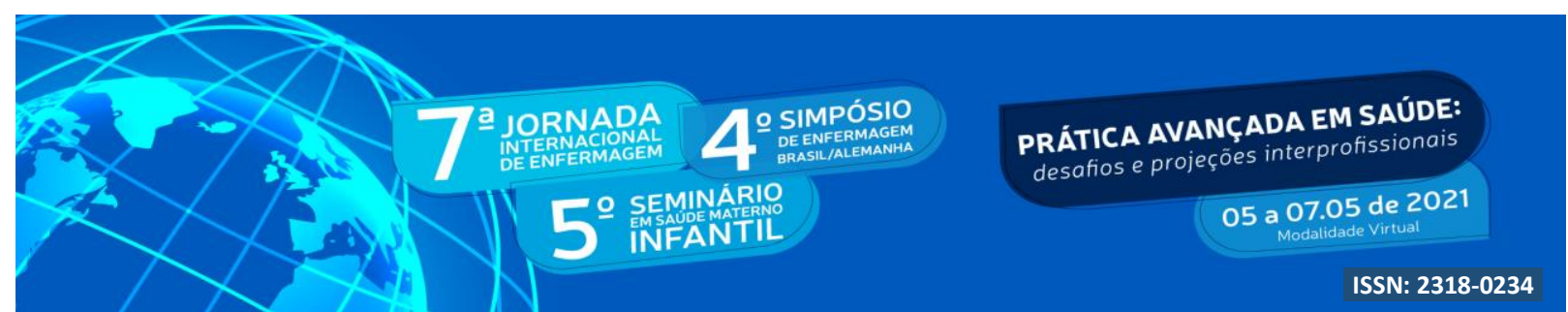

OLIVEIRA, H. V.; SOUZA, F. S. Do conteúdo programático ao sistema de avaliação: Reflexões educacionais em tempos de pandemia (COVID-19). Boletim de Conjuntura, Boa Vista, v. 2, n. 5, p. 15-24, 2020. Disponível em: https://revista.ufrr.br/boca/article/view/OliveiraSouza/2867.

ORGANIZAÇÃO INTERNACIONAL DO TRABALHO. A condição dos professores: recomendação internacional de 1966, um instrumento para a melhoria da condição dos professores. Genebra: OIT/ UNESCO, 1984.

PIAGET, Jean. A formação do símbolo na criança: imitação, jogo e sonho, imagem e representação (Cabral, A.; Oiticica, C.M., Trad.). 2a Ed. Rio de Janeiro: Zahar; Brasília: INL, 1975.

UNIVERSIDADE FRANCISCANA. Projeto pedagógico do curso de graduação em psicologia. Santa Maria, 2016. Disponível em: http://www.ufn.edu.br/site/ensino/graduacao/psicologia. 